\title{
Dual-polarization C-band weather radar algorithms for rain rate estimation and hydrometeor classification in an alpine region
}

\author{
H. Paulitsch, F. Teschl, and W. L. Randeu \\ Department of Broadband Communications, Graz University of Technology, Graz, Austria
}

Received: 15 September 2008 - Revised: 2 February 2009 - Accepted: 25 February 2009 - Published: 9 March 2009

\begin{abstract}
Dual polarization is becoming the standard for new weather radar systems. In contrast to conventional weather radars, where the reflectivity is measured in one polarization plane only, a dual polarization radar provides transmission in either horizontal, vertical, or both polarizations while receiving both the horizontal and vertical channels simultaneously. Since hydrometeors are often far from being spherical, the backscatter and propagation are different for horizontal and vertical polarization. Comparing the reflected horizontal and vertical power returns and their ratio and correlation, information on size, shape, and material density of cloud and precipitation particles can be obtained. The use of polarimetric radar variables can therefore increase the accuracy of the rain rate estimation compared to standard $Z-R$ relationships of non-polarimetric radars. It is also possible to derive the type of precipitation from dual polarization parameters, although this is not an easy task, since there is no clear discrimination between the different values. Fuzzy logic approaches have been shown to work well with overlapping conditions and imprecisely defined class output.

In this paper the implementation of different polarization algorithms for the new Austrian weather radar on Mt. Valluga is described, and first results from operational use are presented. This study also presents first observations of rain events in August 2007 during the test run of the radar. Further, the designated rain rate estimation and hydrometeor classification algorithms are explained.
\end{abstract}

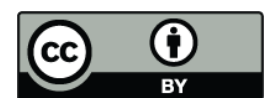

Correspondence to: H. Paulitsch

(helmutp@radar.tugraz.at)

\section{Introduction}

In summer 2006, the fifth Austrian C-band weather radar was installed to improve the measurement of rain in the western part of Austria. It is located on Mt. Valluga at $2809 \mathrm{~m}$ ASL at the border between the provinces Vorarlberg and Tyrol. The radar is operated by Austro Control, the Austrian air navigation services provider. As opposed to the existing radars, this radar is equipped with dual polarization capabilities.

The Valluga Weather radar is an EEC SidPol version. It is equipped with an ortho-mode feed and electronically controlled waveguide signal routing to provide transmission in either horizontal, vertical, or both polarizations, while receiving both the horizontal and vertical channels simultaneously by two separate receive chains. A mode change from simultaneous transmission to either vertical or horizontal transmission is required for Linear Depolarization Rate $(L D R)$ measurement. The characteristics of the radar are summarized in Table 1.

Dual polarization radars transmit horizontally and vertically polarized electromagnetic pulses and measure the respective reflected powers. By comparing the reflected horizontal and vertical power returns and their ratio and correlation, information on the type, size and shape of cloud and precipitation particles can be obtained. In comparison with a conventional radar system dual polarization systems provide additional fundamental variables:

\subsection{Differential reflectivity $Z_{D R}$}

Differential reflectivity is the ratio of the horizontal and vertical power returns. $Z_{D R}$ provides information about particle properties, such as the shape of rain drops. If the majority of the particles in the measured radar volume have a nonspherical shape, and polarization is aligned with the particle axes, the power return will be greater for one polarization than for the other. For large rain drops with an oblate shape,

Published by Copernicus Publications on behalf of the European Geosciences Union. 
Table 1. Characteristics of the Valluga radar during test run.

\begin{tabular}{ll}
\hline Altitude & $2809 \mathrm{~m}(\mathrm{~m} . \mathrm{s} .1)$. \\
Frequency & $5.625 \mathrm{GHz}$ \\
Beamwidth & $0.95^{\circ} \mathrm{H} / 0.9^{\circ} \mathrm{V}$ \\
Transmitter type & Coaxial magnetron \\
Peak power & $250 \mathrm{~kW}$ \\
Pulse length & $0.8 \mu \mathrm{s}$ \\
Pulse repetition rate & $1000 \mathrm{~s}^{-1}$ \\
Samples per integration & 50 \\
Rotation rate & $4 \mathrm{RPM}\left(24^{\circ} / \mathrm{sec}\right)$ \\
Range resolution & $125 \mathrm{~m}$ \\
Number of range-gates & 960 \\
Maximum range & $120 \mathrm{~km}$ \\
Elevation angles & 14 from $-1.8^{\circ}$ to $+90^{\circ}$ \\
& $(-1.8,-0.8,-0.1,1.0,2.0,2.8,4.2$, \\
& $7.7,10.2,13.7,19.7,30.2,60.0,90.0)$ \\
\hline
\end{tabular}

the horizontal power return will be greater than for the vertical and therefore the $Z_{D R}$ value will be positive (expressed in $\mathrm{dB}$ ). Small rain drops or light hail particles are more like spherical and result in $Z_{D R}$ values near one or zero $\mathrm{dB}$. Negative $\mathrm{dB}$ values can occur for large hail.

\subsection{Correlation coefficient $\rho_{H V}$}

The correlation coefficient, $\rho_{H V}$, is a measure of the correlation between the reflected horizontal and vertical power returns. Generally in rain the correlation is high and $\rho_{H V}$ is close to one. In regions where there is a mixture of precipitation types, such as rain and snow, or where the particle properties are highly irregular, the correlation is much lower and can result in $\rho_{H V}$ values down to 0.8 for example for wet snow.

\subsection{Differential phase shift $\phi_{D P}$}

The differential phase shift, $\phi_{D P}$, is the phase shift that occurs between the horizontally- and vertically- polarized pulses along the propagation path. The phase shift is caused by variations in the wave propagation speed, when the electromagnetic pulses encounter precipitation particles of different sizes and shapes.

\subsection{Specific differential phase $K_{D P}$}

The specific differential phase, $K_{D P}$, is the range derivative of the differential phase $\phi_{D P}$. Since the phase shift is influenced by propagation effects like attenuation or beam shielding, which reduce the power return, it can be used for attenuation correction. $K_{D P}$ is also a good estimator of rain rate.

\subsection{Linear depolarization ratio $L D R$}

$L D R$ is the ratio of the cross-polar to the co-polar power return from a horizontally or a vertically polarized pulse. It is

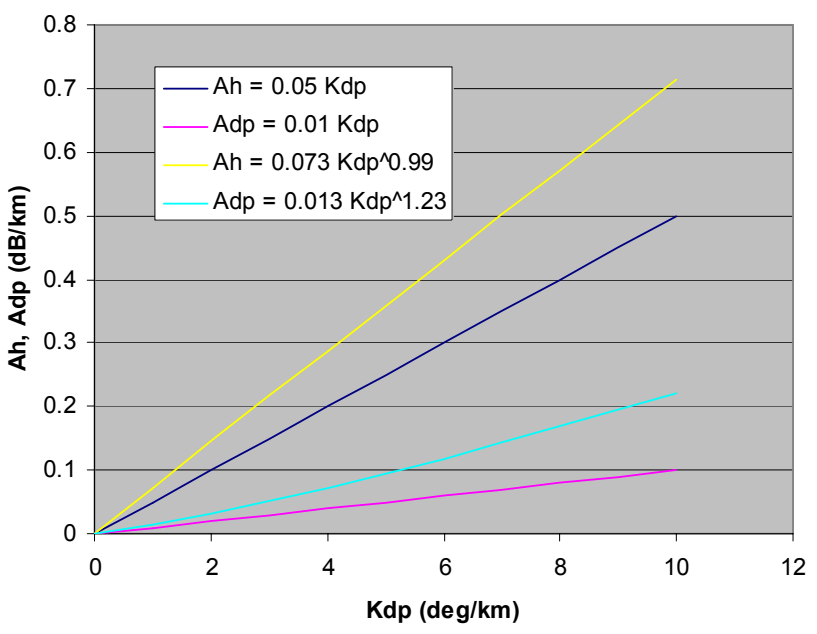

Fig. 1. Attenuation correction estimators for C-band.

sensible to particle orientation and canting and is also a good indicator of regions where a mixture of precipitation types occurs or ground clutter is present.

\section{Attenuation correction}

At $\mathrm{C}$-band wavelength, the attenuation along the propagation path due to precipitation particles can degrade radar measurements to a considerable degree. In order to make accurate rainfall estimates, an attenuation correction scheme for $Z_{H}$ (Horizontal Reflectivity) and $Z_{D R}$ should be used. The attenuation factors $A_{H}$ and $A_{D P}$ can be calculated using different methods depending on the type of measurements involved. Studies from Bringi et al. (1990) and Smyth and Illingworth (1998) show different correction methods. Typically methods using the specific differential phase $\left(K_{D P}\right)$ are applied. The following relations from Bringi and Chandrasekhar (2001) show a nearly linear relation between attenuation and $K_{D P}$ :

$$
\begin{aligned}
& A_{H}=0.073 K_{D P}^{0.99} \\
& A_{D P}=0.013 K_{D P}^{1.23}
\end{aligned}
$$

where $A_{H}$ is the specific attenuation in $\mathrm{dB} / \mathrm{km}$ for horizontal polarization, $A_{D P}$ is the specific differential attenuation in $\mathrm{dB} / \mathrm{km}$ and $K_{D P}$ is the specific differential phase in $\mathrm{deg} / \mathrm{km}$.

$A_{H}$ and $A_{D P}$ are calculated for every radar volume element. The resulting attenuation on a certain path is the sum of all attenuation factors (in $\mathrm{dB}$ ) along the path. The horizontal reflectivity $Z_{H}$ and the differential reflectivity $Z_{D R}$ are then raised by the respective values. Such iterative approaches can sometimes be unstable and can lead to unrealistically high reflectivity values. Therefore a simpler approach using linear estimators for attenuation and differential attenuation is used for the Valluga radar. The linear relationship 
also allows calculating the attenuation at a certain range-gate directly from the differential phase shift:

$A_{H}=0.05 K_{D P}$

$A_{D P}=0.01 K_{D P}$

These correction factors are among the lowest that are found in literature. This cautious approach was chosen since the radar operates in a height where mixed phase or solid precipitation is likely to occur. The different correction factors are compared in Fig. 1.

\section{Rain rate estimation}

Rain rate estimation is one of the main operational applications of weather radars. The use of polarimetric radar variables is expected to increase the accuracy of the rain rate estimation compared to the standard $Z-R$ relationship for nonpolarimetric radars, since polarimetric radars can provide a more accurate description of the target. In addition to the horizontal reflectivity $\left(Z_{H}\right)$, especially the specific differential phase $\left(K_{D P}\right)$ and the differential reflectivity $\left(Z_{D R}\right)$ are applied in rain rate algorithms of polarimetric weather radars. A detailed evaluation of these rainfall algorithms is given by Bringi and Chandrasekhar (2001). The typical form of these estimators is given below:

$$
\begin{aligned}
& R\left(K_{D P}\right): R=a K_{D P}^{b} \\
& R\left(K_{D P}, Z_{D R}\right): R=c K_{D P}^{a} 10^{(0.1 b Z D R)} \\
& R\left(Z_{H}, Z_{D R}\right): R=c Z_{H}^{a} 10^{(0.1 b Z D R)}
\end{aligned}
$$

where $R$ is the rain rate.

In a previous study (Teschl et al., 2008), polarimetric radar variables were simulated for $\mathrm{S}$-, $\mathrm{C}$ - and $\mathrm{X}$-band wavelengths in order to establish radar rainfall estimators for the alpine region of the form $R\left(K_{D P}\right), R\left(Z_{H}, Z_{D R}\right)$, and $R\left(K_{D P}, Z_{D R}\right)$. For the simulation, drop size distributions of hundreds of 1-minute-rain episodes were obtained from 2DVideo-Distrometer measurements in the mountains of Styria, Austria. Also the influence of different rain drop shape models was investigated. When assuming the model of Brandes et al. (2002) the C-band rain rate estimation algorithms are

$$
\begin{aligned}
& R\left(K_{D P}\right): R=18.77 K_{D P}^{0.769} \\
& R\left(K_{D P}, Z_{D R}\right): R=22.4 K_{D P}^{0.77} 10^{-0.072 Z D R} \\
& R\left(Z_{H}, Z_{D R}\right): R=0.015 Z_{H}^{0.82} 10^{-0.290 Z D R}
\end{aligned}
$$

with $R$ in $\mathrm{mm} / \mathrm{h}, K_{D P}$ in ${ }^{\circ} / \mathrm{km}, Z_{H}$ in $\mathrm{mm}^{6} \mathrm{~m}^{-3}$ and $Z_{D R}$ in $\mathrm{dB}$.

It is intended to use theses estimators in combination with the attenuation correction method described above and to verify the results with ground based observations.

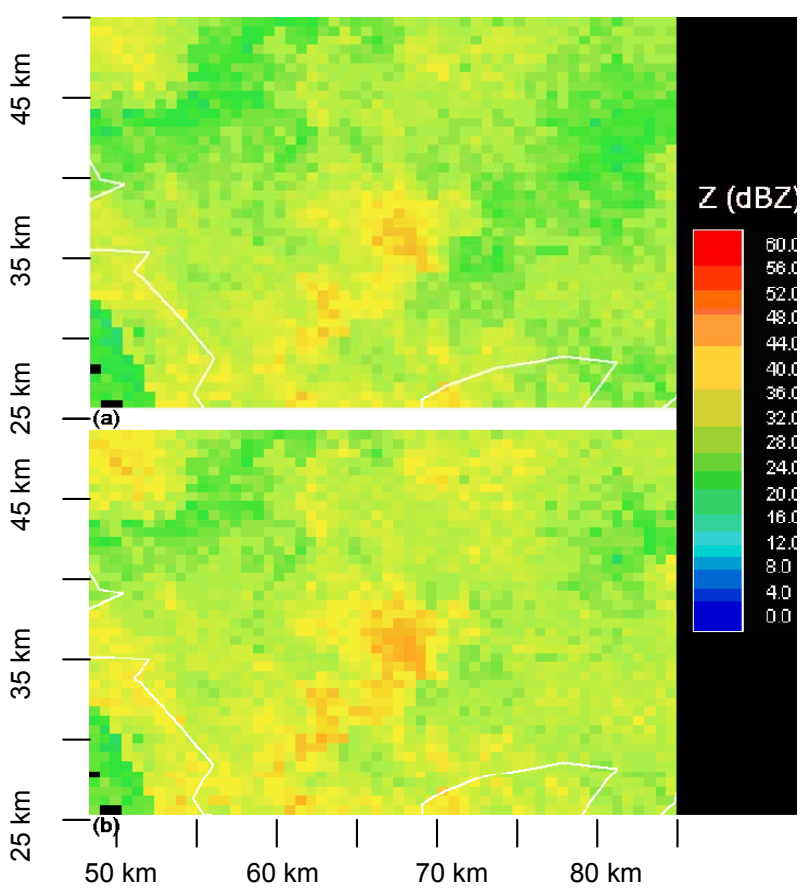

Fig. 2. Reflectivity $Z_{H}$ of a rain cell seen from the Valluga radar (a) without attenuation correction (b) with attenuation correction $A_{H}=0.05 K_{D P}$.

\section{Hydrometeor classification}

For the automatic hydrometeor type classification of the Valluga radar a classification scheme based on fuzzy logic is implemented. Fuzzy logic has several advantages over a Boolean approach, since it can manage to classify in the presence of imprecisely defined class output and cope well with overlapping conditions. The implementation for the Valluga radar is based on the CSU scheme for S-band (Liu, and Chandrasekar, 2000; Lim et al., 2005) with adaptations for C-band weather radars (L. Baldini, personal communication, 2007).

The first step in the classification process is the fuzzification of the input parameters. For the radar parameters $Z_{H}$, $Z_{D R}, \rho_{H V}, K_{D P}$ and $L D R$ as well as for the altitude of the observation, membership functions are defined for each of the different hydrometeor types. They are in general beta functions of the form:

$$
\beta(x, m, a, b)=\frac{1}{1+\left\{[(x-m) / a]^{2}\right\}^{b}}
$$

The beta membership functions map an input value $\mathrm{x}$ to an output value in the range of $[0,1]$. The parameters have the following meaning: $m$ locates the centre of the curve while $a$ and $b$ define the width and the slope.

An example of beta membership functions for $Z_{H}$ is shown in Fig. 3. There are similar functions for $L D R, \rho_{H V}$ and the height. For $Z_{D R}$ and $K_{D P}$ two-dimensional functions are used, since these parameters are dependent on $Z_{H}$. 


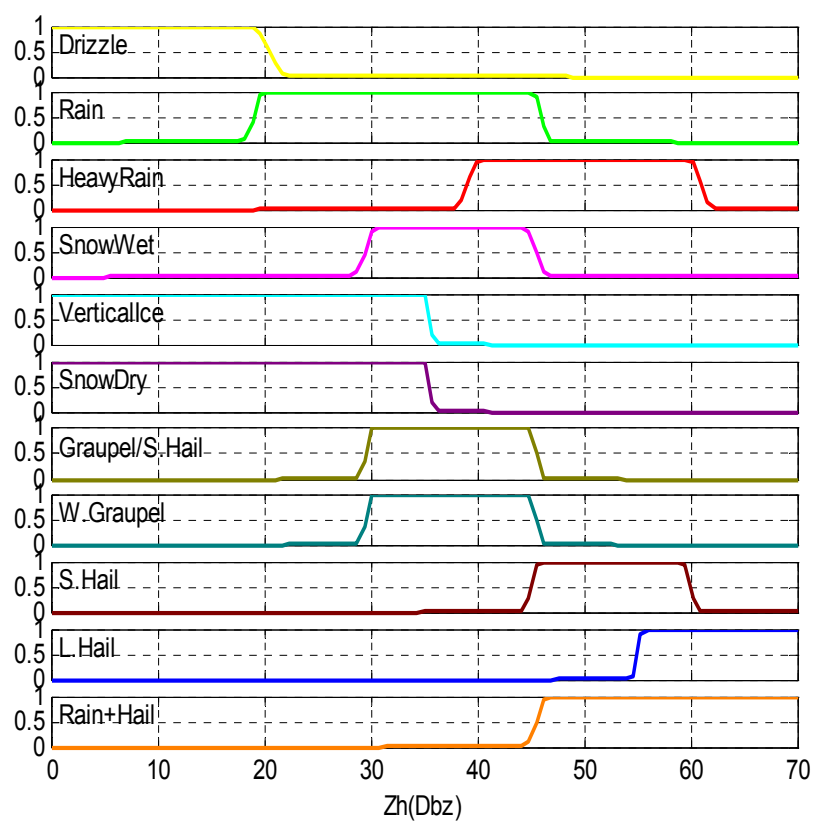

Fig. 3. Membership functions for $Z_{H}$ (Baldini, 2007).

Figure 4 shows an example of two-dimensional functions for $Z_{D R}$ and $Z_{H}$ (Baldini, 2007).

For a set of given input parameters the most likely hydrometeor type is the one with the highest rule strength value. The rule strength is defined as:

$R j=\mu_{j}^{Z h}(Z h) \times \mu_{j}^{H}($ Height $) \times$
$\left[\begin{array}{l}w_{j}^{Z d r} \mu_{j}^{Z d r}(Z d r)+w_{j}^{K d p r} \mu_{j}^{K d p}(K d p)+ \\ w_{j}^{L D R} \mu_{j}^{L D R}(L D R)+w_{j}^{\rho h v} \mu_{j}^{\rho h v}(\rho h v)\end{array}\right]$

where $\mu$ are the beta functions and $w$ are weight factors.

Eleven hydrometeor types including drizzle, light and heavy rain, dry and wet snow, and different intensities of graupel and hail are defined.

\section{Results}

The radar started routine operation in October 2007, using single polarization only. In a test phase before this time several dually polarized measurements have been collected. Unfortunately no $L D R$ scans were available and also the $K_{D P}$ parameter was not calculated by the radar software. Therefore it was not possible to test the $K_{D P}$ based rain rate estimators. Without these parameters also the fuzzy logic classification scheme must make decisions based on fewer inputs, which consequently leads to a higher variance.

The radar images below show a precipitation event with mostly wide spread precipitation, on 29 August 2007 at 10:37 local time. During this event reflectivity values up to $48 \mathrm{dBZ}$ were measured in some embedded cells in the northeastern part of the image (Fig. 5). All figures show a constant

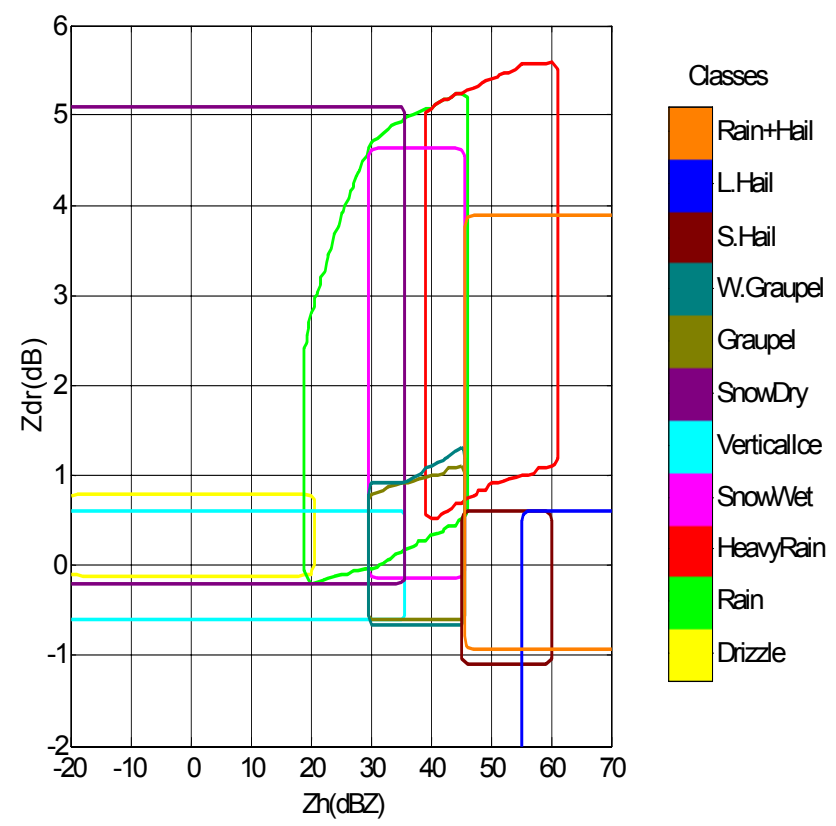

Fig. 4. Membership functions for $Z_{D R}$ and $Z_{H}$ (Baldini, 2007).

altitude plan position indicator (CAPPI) at a height of $2.5 \mathrm{~km}$ and a vertical cross section along the line indicated in Fig. $5 \mathrm{a}$.

Figures 6,7 and 8 show the differential reflectivity $Z_{D R}$, the correlation coefficient $\rho_{H V}$ and the differential phase $\phi_{D P}$, respectively. For a large area in the vertical cross section no $\rho_{H V}$ and $\phi_{D P}$ parameters are available. This causes also the hydrometeor classification to fail in this area.

The result of the classification is shown in Fig. 9. The hydrometeor classification indicates dry and wet snow, rain and wet graupel in the CAPPI. In the vertical cross section dry snow is the predominant hydrometeor type above $4 \mathrm{~km}$, which changes to heavy rain, wet snow, wet graupel and rainthail below.

An example for the attenuation correction of a rain cell for the reflectivity factor $Z_{H}$ is shown in Fig. 2. Even with these low correction factors, differences of about $3 \mathrm{~dB}$ between the corrected and the uncorrected data can be seen. A certain radar beam at an elevation of $-0.1^{\circ}$ and an azimuth of $56^{\circ}$ degrees through this area has been further analyzed. The profile of the polarization parameters along the beam can be seen in Fig. 10. Figure 11 compares the attenuated with the corrected reflectivity. The parameters are averaged over four range gates to give the same $500 \mathrm{~m}$ resolution as in Fig. 2. Even with this range-averaging the noise in $\phi_{D P}$ is quite large, especially for ranges beyond $50 \mathrm{~km} . Z_{D R}$ also shows rather large positive values with a mean value around $4 \mathrm{~dB}$. 

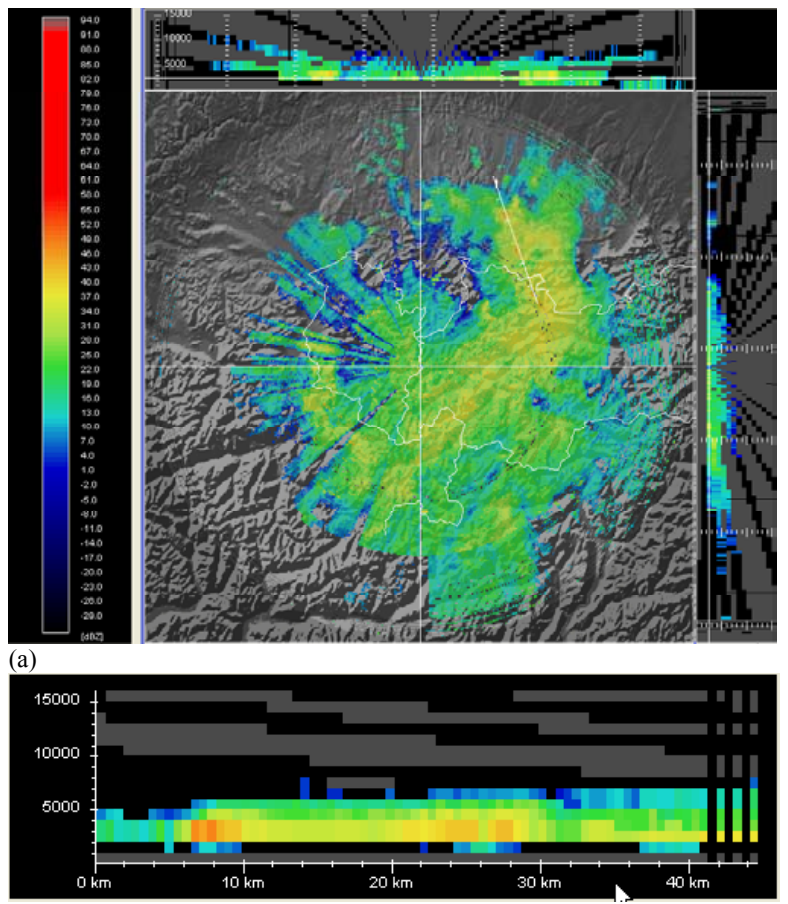

(b)

Fig. 5. $Z_{H}$ (dBZ), 29 August 2007, 10:37 (a) CAPPI $2.5 \mathrm{~km}$ (b) Vertical cross section.
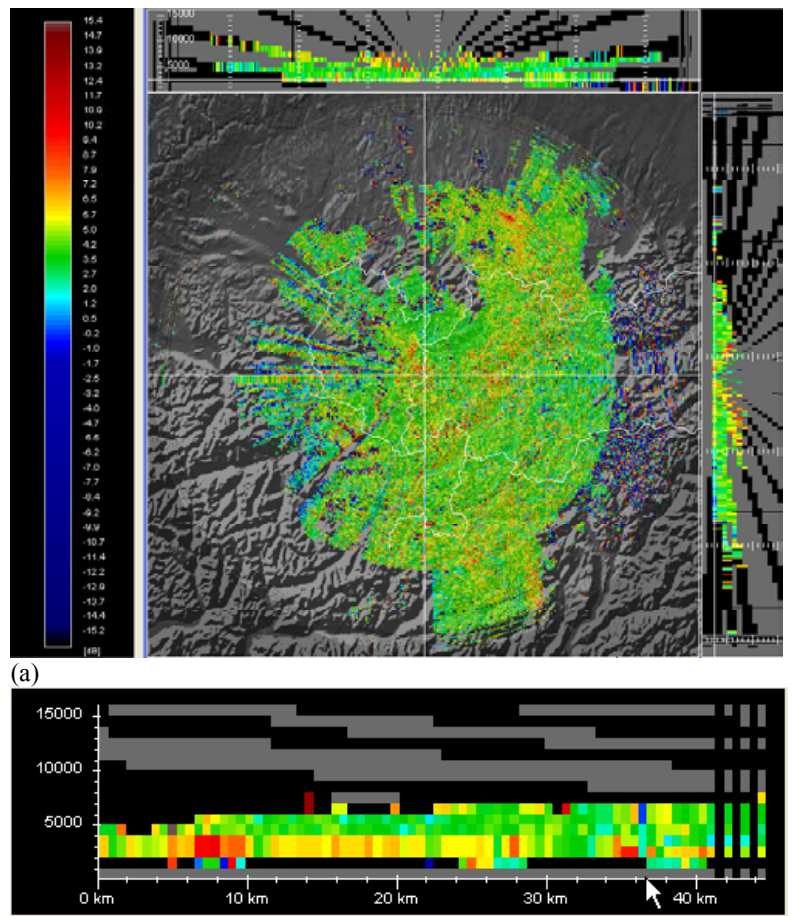

(b)

Fig. 6. $Z_{D R}(\mathrm{~dB}), 29$ August 2007, 10:37 (a) CAPPI $2.5 \mathrm{~km}$ (b) Vertical cross section.
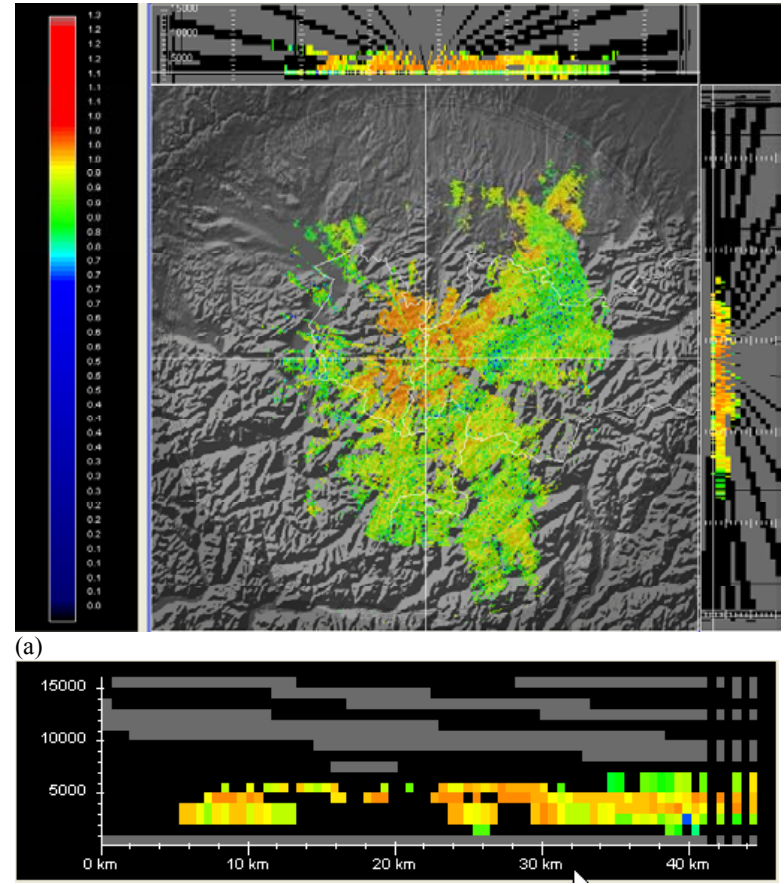

(b)

Fig. 7. $\rho_{H V}, 29$ August 2007, 10:37 (a) CAPPI $2.5 \mathrm{~km}$ (b) Vertical cross section.
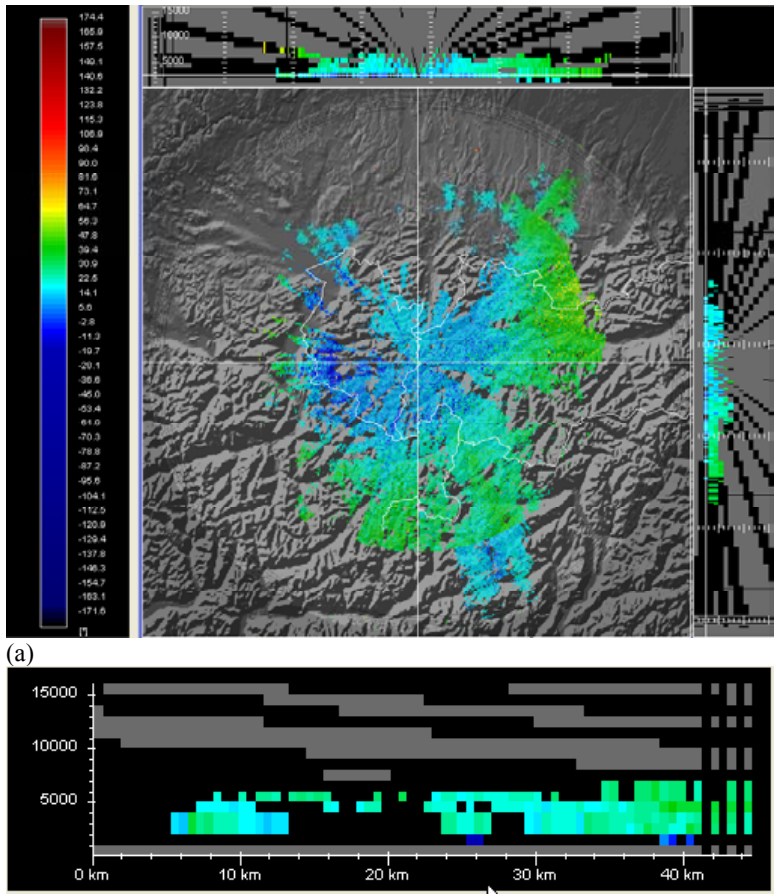

(b)

Fig. 8. $\phi_{D P}$ (deg), 29 August 2007, 10:37 (a) CAPPI $2.5 \mathrm{~km}$ (b) Vertical cross section. 

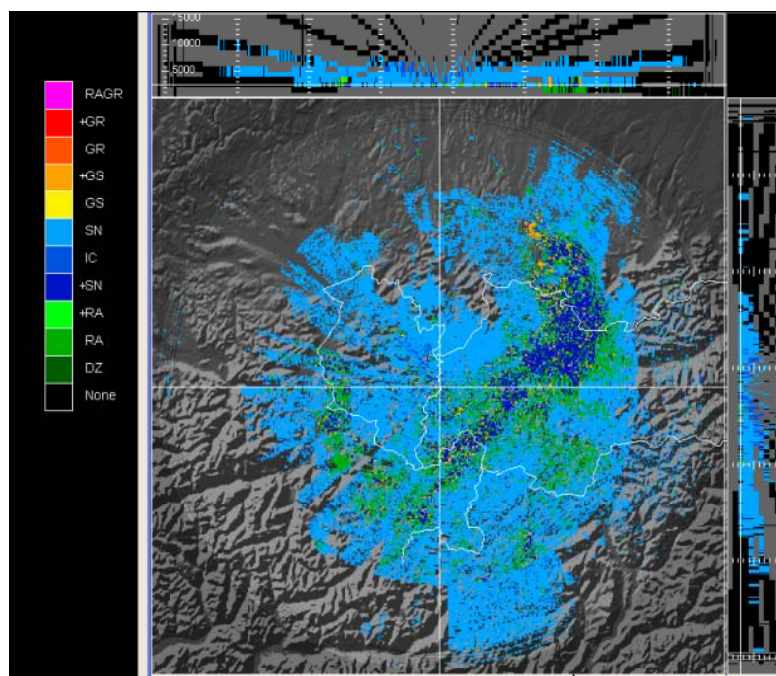

(a)

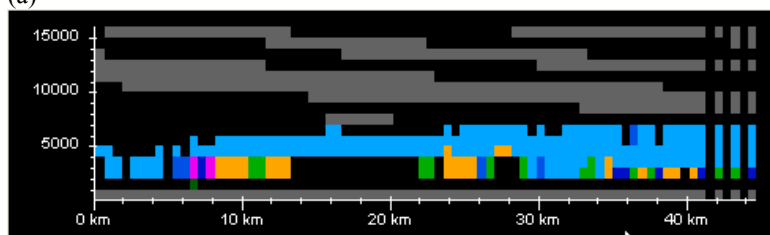

(b)

Fig. 9. Hydrometeor classification, 29 August 2007, 10:37 (a) CAPPI $2.5 \mathrm{~km}$ (b) Vertical cross section (RAGR: rain and hail, +GR: large hail, GR: hail, +GS: wet graupel, GS: graupel, SN: snow, IC: ice, $+\mathrm{SN}$ : wet snow, $+\mathrm{RA}$ : heavy rain, RA: rain, DZ: drizzle).

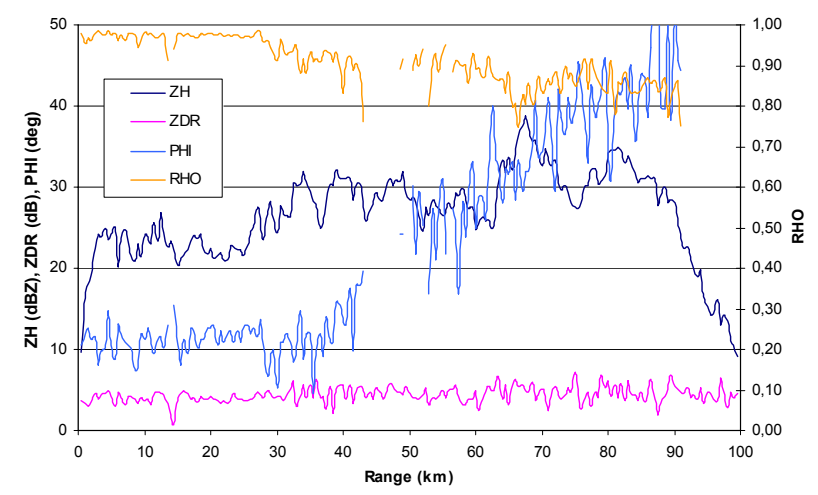

Fig. 10. Radar parameters along a single ray (azimuth $56^{\circ}$, elevation $\left.-0.1^{\circ}\right)$.

\section{Conclusion and outlook}

This study presents first observations of precipitation events during the test run of the Valluga C-band weather radar. Since the radar is located at more than $2800 \mathrm{~m}$ ASL, precipitation often occurs in solid or in mixed phase form. First promising results of the classification algorithm have shown the occurrence of different hydrometeor types like graupel, rain and snow, which is the predominant precipitation type

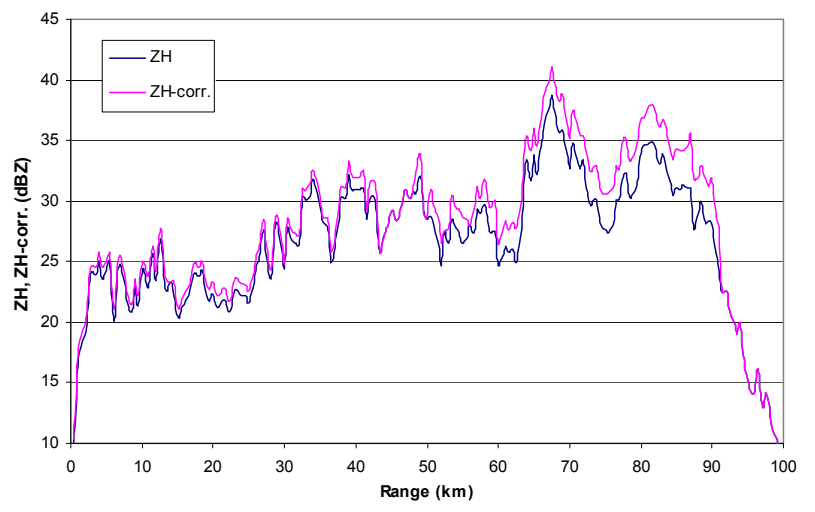

Fig. 11. Effect of attenuation correction on $Z_{H}$ along a single ray (azimuth $56^{\circ}$, elevation $-0.1^{\circ}$ ).

at this height. An important future step will be to adjust the current hydrometeor classification parameters (membership functions and weight factors) for reliable use in the alpine region.

Acknowledgement. The authors gratefully acknowledge the provision of Valluga weather radar data by Austro Control, the Austrian air navigation services provider (Dept. of Aviation Meteorology, Mr. Kaltenböck).

Edited by: S. C. Michaelides

Reviewed by: two anonymous referees

\section{References}

Baldini, L., Gorgucci, E., Chandrasekar, V., and Peterson, W.: Implementations of CSU hydrometeor classification scheme for Cband polarimetric radars, 32nd Conference on Radar Meteorology, September 2005, Albuquerque, NM 2005.

Brandes, E., Zhang, G., and Vivekanandan, J.: Experiments in rainfall estimation with a polarimetric radar in a subtropical environment, J. Appl. Meteor., 41, 674-685, 2002.

Bringi, V. N. and Chandrasekhar, V.: Polarimetric Doppler Weather Radar. Principles and Applications. Cambridge University Press, NY, 636 pp., 2001.

Lim, S., Chandrasekar, V., and Bringi, V. N.: Hydrometeor Classification System Using Dual-Polarization Radar Measurements: Model Improvements and In Situ Verification, IEEE Trans. Geosci. Remote Sens., 43, 792-801, 2005.

Liu, H., and Chandrasekar, V.: Classification of Hydrometeors Based on Polarimetric Radar Measurements: Development of Fuzzy Logic and Neuro-Fuzzy Systems, and In Situ Verification, J. Atmos. Oceanic Technol., 17, 140-164, 2000.

Smyth, T. J. and Illingworth, A. J.: Correction for attenuation of radar reflectivity using polarization data, Quart. J Roy. Meteor. Soc., 124, 2393-2415, 1998.

Teschl, F., Randeu, W. L., Schönhuber, M., and Teschl, R.: Simulation of polarimetric radar variables in rain at S-, C- and X-band wavelengths, Adv. Geosci., 16, 27-32, 2008, http://www.adv-geosci.net/16/27/2008/. 